\title{
Evaluation of locally available synthetic macro fibres in a single-fibre pullout test in concrete
}

\author{
C M Odendaal, A J Babafemi, R Combrinck, W I de Villiers, W P Boshoff
}

There is increasing use of synthetic macro fibres in concrete applications. However, the performance of these fibres varies, based on various factors. This study investigates the fibre/ matrix interface performance of four types of synthetic macro fibres locally available in the South African construction market. The influence of water-cement ratio $(w / c)$, fibre embedment length, fibre properties and fibre snubbing angle on the single-fibre pull-out behaviour is studied in this paper. The influence of some of these properties on the compressive strength is also evaluated. Three mix designs and four fibre types were used for the investigation. All tests were performed in a controlled climate room. Specimens with single fibres were tested in a Universal Testing Machine. Scanning Electron Microscope (SEM) images of pulled out fibres were examined for inferences. The results have shown that $\mathrm{w} / \mathrm{c}$ has no influence on the pull-out load of synthetic macro fibres. However, the pull-out load increases with increase in fibre embedment length and equivalent fibre diameter. Pull-out load increases for flat fibres bent along their strong axis as the fibre snubbing angle increases. While crimped fibres with improved geometry show optimum pull-out performance when pulled out perpendicularly to the crack plane, flat fibres performed better at the snubbing angles tested. SEM images also show more surface damage on fibres with irregular geometry.

\section{INTRODUCTION}

Concrete is widely used in the construction industry. Due to the inherent weakness in the tensile properties of concrete, it is conventionally reinforced with steel bars. More recently the use of short discrete fibres in reinforcing concrete has increased significantly. However, it is still a matter of debate if fibres can completely replace steel reinforcement in concrete. The functions of fibres in concrete vary, depending on the type (steel, synthetic, etc) and size (micro or macro). While they mitigate shrinkage in some cases, their main function is in the control of crack opening, thereby enhancing residual tensile properties and durability in the cracked phase of cement composites.

Due to the bridging mechanism of fibres in cracked cementitious composites, significant improvement in properties, such as toughness (Buratti et al 2011), fatigue resistance (Buratti et al 2011), impact resistance (Mindess \& Zang 2009), flexural strength (Hsie et al 2008; Lie \& Kodur 1996) and reduction in plastic shrinkage cracking (Boshoff \& Combrinck 2013) have been reported. The two most widely used fibres in civil engineering works are steel and synthetic fibres (Buratti et al 2011). Areas of application include concrete ground slabs (Alani \& Beckett 2013; Sorelli et al 2006), concrete pipes (de la Fuente et al 2013), precast structural elements (Ferrara \& Meda 2006) and shotcreting (Bernard 2004).

Lately the development and use of larger monofilament synthetic macro fibres (also called structural fibres) have been on the increase, which is an indication of their viability as an alternative to steel fibres and steel reinforcing bars. They have better resistance to chemicals (Wang et al 1987), do not deteriorate with age (Hannant 1998), and are cheaper and lighter (Richardson 2005). However, the mechanical performance of synthetic macro fibres in concrete could significantly vary due to a number of factors, such as geometry (straight, flat or crimped), diameter, length, tensile strength, etc. The effect of temperature on the properties of synthetic fibres due to exposure of concrete to long periods of heat and sun radiation could have a significantly adverse effect on their properties. The application of macro synthetic fibre is typically limited to shotcrete and concrete floor-on-grade applications, where the

\section{JOURNAL OF THE SOUTH AFRICAN INSTITUTION OF CIVIL ENGINEERING}

ISSN 1021-2019

Vol 60 No 1, March 2018, Pages 21-30, Paper 1744

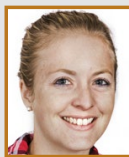

COURTNEY ODENDAAL, who is an Associate Member of SAICE, is a structural engineer at Moroff and Kühne Consulting Engineers, where she is involved in the structural design of multi-storey buildings. Prior to this she worked at Aurecon for two and a halfyears in a similar capacity. She obtained an MEng in Civil Engineering from Stellenbosch University in 2014, with research focusing on performance-based specifications for locally available macro synthetic fibres. Contact details

Moroff and Kuhne Consulting Engineers

Suite 307, The Regent, 19-33 Regent Road, Sea Point Cape Town 8005, South Africa

T: +27 21 4348176, E: courtney.odendaal1@gmail.com

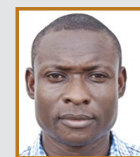

DRA JOHN BABAFEMI obtained his PhD from the Department of Civil Engineering. Stellenbosch University, in March 2015, and was a postdoctora research fellow at the Unit for Construction Materials in the same Department between 2016 and 2017. He is currently lecturing at the Department of Building at the

Obafemi Awolowo University, lle-Ife, Nigeria. His research interest is in the areas of fibre-reinforced concrete, concrete durability and use of supplementary cement materials. He has several research publications to his credit. Contact details

Unit for Construction Materials, Department of Civil Engineering, Stellenbosch University, Stellenbosch 7602

T: +27 21808 4498, E: ajbabafemi@oauife.edu.ng

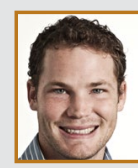

DR RIAAN COMBRINCKis a senior lecturer at Stellenbosch University, where he also obtained both his MSc and PhD on the cracking of plastic concrete in slab-like elements. He is part of the Unit of Construction Materials which concentrates on teaching, research and consulting, and also the head of the structural laboratory, both within the Civil Engineering Department. He has been involved in various commercial and academic research projects, and has supervised several postgraduate students. He also authored or co-authored several journal and conference publications during the past seven years.

Contact details

Unit for Construction Materials, Department of Civil Engineering Stellenbosch University, Stellenbosch 7602

T: +27 21808 4946, E: rcom@sun.ac.za

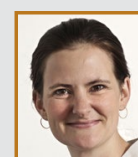

WIBKE DE VILLIERS is a lecturer at Stellenbosch University, where she also obtained her MSc on web compression elements in parallel chord trusses. She is currently working towards a PhD on the development of performance-based specifications for alternative masonry units. She is part of the Unit of Construction Materials which concentrates on teaching, research and consulting within the Civil Engineering Department. She has supervised a number of postgraduate students and authored or co-authored several publications during the past seven years. Prior to this she spent two years at Aurecon as a structural design engineer.

Contact details

Unit for Construction Materials, Department of Civil Engineering Stellenbosch University, Stellenbosch 7602

T:+27 21808 4072,E:wdv@sun.ac.za

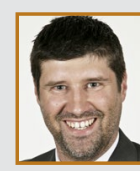

PROF BILLY BOSHOFF is head of the Unit for Construction Materials at Stellenbosch University. He was also head of the Structural Engineering Division for seven years and served as the president of the Concrete Society of Southern Africa from 2012 to 2014 He completed his PhD at Stellenbosch University in the field of fibre-reinforced concrete in 2007 and has published more than 78 papers in journals and conference proceedings. His research interest is in the field of construction materials, but more specifically fibre-reinforced concrete, concrete cracking in the fresh state, as well as unconventional and eco-friendly construction materials.

Contact details

Unit for Construction Materials, Department of Civil Engineering

Stellenbosch University, Stellenbosch 7602

T: +2721808 4445, E: bboshoff@sun.ac.za

Keywords: synthetic macro fibres, pull-out load, fibre-reinforced concrete, FRC, single-fibre pull-out, embedment length, critical fibre length, scanning electron microscope, SEM 


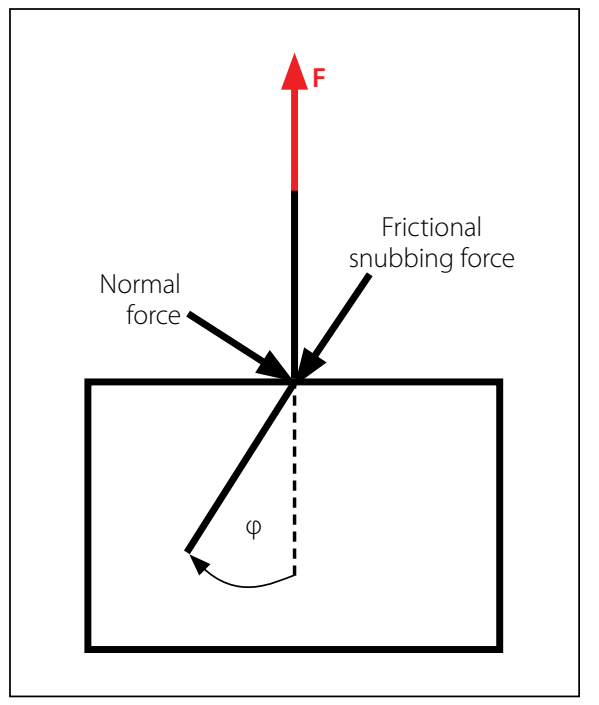

Figure 1 Fibre snubbing angle

\section{Table 1 Properties of synthetic macro fibres}

\begin{tabular}{|c|l|c|}
\hline $\begin{array}{c}\text { Fibre } \\
\text { classes }\end{array}$ & $\begin{array}{c}\text { Commercial } \\
\text { name }\end{array}$ & $\begin{array}{c}\text { Cross-sectional } \\
\text { shape }\end{array}$ \\
\hline Fibre 1 & Rocstay & $X$ \\
\hline Fibre 2 & Rocstay & $X$ \\
\hline Fibre 3 & Geotex 500 Series & Oval \\
\hline Fibre 4 & Goetex 600 Series & Rectangular \\
\hline Fibre 5 & Chryso & Rectangular \\
\hline
\end{tabular}

yield-line design approach (plastic design) has to be followed to harness the advantages of the fibres (Concrete Society 2014).

There is considerable global scepticism regarding the use of synthetic fibres for reinforcing concrete, with South Africa not being exempted. The scepticism is strengthened by the fact that synthetic macro fibres have low stiffness compared to steel fibres, and have been reported to creep significantly more than steel (Babafemi \& Boshoff 2015; Pujadas et al 2017). However, this should not discourage its use, but requires that certain design guidelines be established for its sensible application (Pujadas et al 2017).

In this paper, the pull-out performance of four locally available synthetic macro fibres in South Africa is evaluated at the single-fibre level. The main objective of this study is to assess the fibre-matrix bond characteristics of these locally available fibres. The fibre-matrix bond characteristics would give an indication of how best each fibre performs. This is done by performing single-fibre pull-out tests at different embedment lengths, as well as different embedment angles to determine the snubbing effect. The fibre snubbing effect is the increase in maximum pull-out force $(F)$ when a fibre is pulled out at an

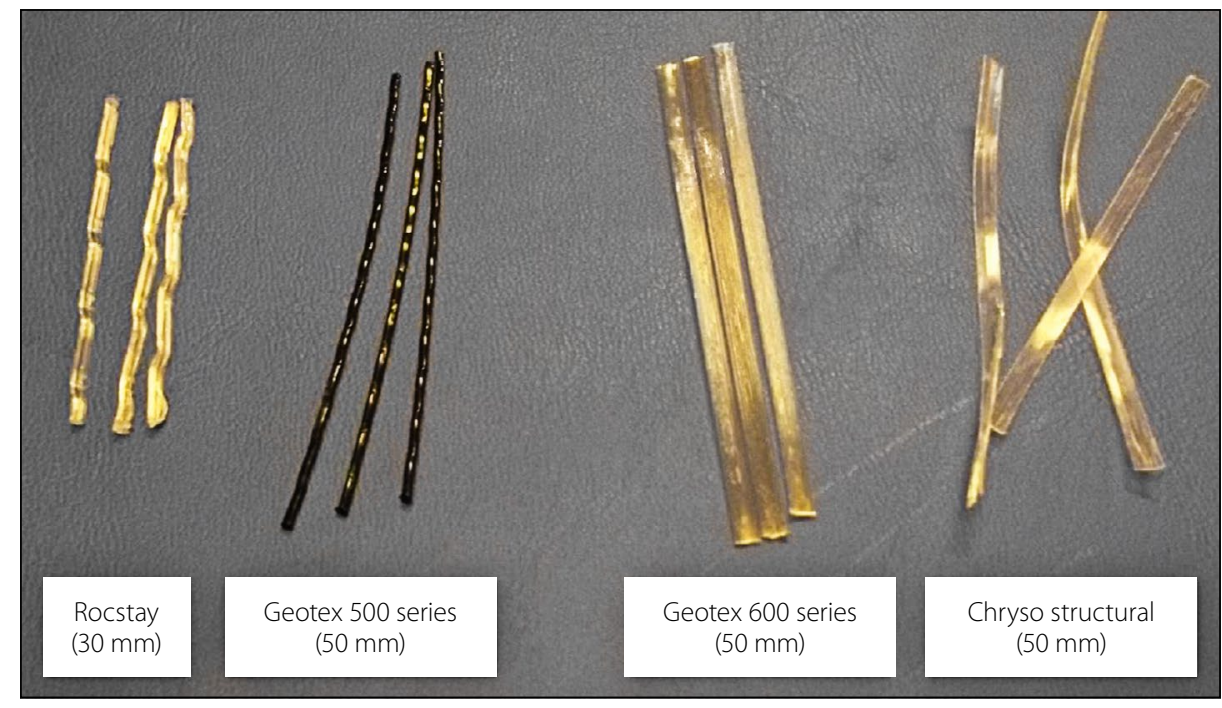

Figure 2 Synthetic (polypropylene) macro fibres

\begin{tabular}{|c|c|c|c|c|c|}
\hline $\begin{array}{l}\text { Longitudinal } \\
\text { geometry }\end{array}$ & $\begin{array}{c}I_{f} \\
(\mathrm{~mm})\end{array}$ & $\begin{array}{l}d_{e(s)} \\
(\mathrm{mm})\end{array}$ & $\begin{array}{c}d_{e} \\
(\mathrm{~mm})\end{array}$ & $\lambda$ & $\begin{array}{c}\sigma_{f} \\
(\mathrm{MPa})\end{array}$ \\
\hline Crimped & 30 & 0.8 & 0.998 & 30.1 & 300 \\
\hline Crimped & 30 & 0.8 & 0.701 & 42.8 & 300 \\
\hline Crimped & 50 & 0.9 & 0.76 & 65.8 & 295 \\
\hline Flat & 50 & 0.8 & 0.907 & 55.1 & 275 \\
\hline Flat & 50 & 0.79 & 0.615 & 81.0 & 336 \\
\hline
\end{tabular}

angle $(\phi)$ as opposed to being pulled out in an aligned fashion, as shown in Figure 1. The uniqueness of this study is to particularly investigate these locally available macro synthetic fibres at the single-fibre level. Further studies are still ongoing to relate their response to the macro-level performance under flexure and shear.

Fibres are randomly distributed in a fibre-reinforced composite. The fibres in the composite take different orientation angles and are embedded at different lengths across a cracked section. The overall performance of the composite is dependent on these factors, and many more. Therefore the aim of the study (of the effect of the insertion length and snubbing angles at the single-fibre level) is to assess the individual factors and their contribution to the overall performance of the reinforced composite. This has aided the development of models accommodating the contributions of fibre embedment length and orientation angle in the prediction of the mechanical response of FRC elements. However, it is not the goal of this study to develop any model accommodating these factors, but to demonstrate that these factors could have an impact on the overall

\section{MATERIALS AND CONCRETE MIX}

\section{Synthetic macro fibres}

Four types of synthetic polypropylene macro fibres, locally available in South Africa, were used, as shown in Figure 2. The fibre properties, both given by the supplier and measured, are shown in Table 1.

Table 1 shows five fibre categories, as Fibres 1 and 2 were supposed to be the same, but a significant change in the measured equivalent diameters was found from the first batch to the second. Therefore their specified equivalent diameters are the performance of FRC elements.

Table 2 Concrete mix design for experimental investigation

\begin{tabular}{|c|c|c|c|c|c|}
\hline $\begin{array}{c}\text { Mix } \\
\left(\mathrm{kg} / \mathrm{m}^{3}\right)\end{array}$ & Water & Cement & w/c & $\begin{array}{c}\text { Coarse } \\
\text { aggregate }\end{array}$ & Sand \\
\hline Mix 1 & 240 & 400 & 0.6 & 782 & 926 \\
\hline Mix 2 & 240 & 480 & 0.5 & 782 & 859 \\
\hline Mix 3 & 240 & 600 & 0.4 & 782 & 759 \\
\hline
\end{tabular}


same. It is clearly indicated where Fibre 1 or Fibre 2 was used.

The equivalent diameter $\left(d_{e}\right)$ of each fibre type was calculated following the procedure outlined in EN 14889-2:2006 (EN 2006) from the measured total fibre mass (up to 50 numbers) of each fibre type. Since the fibres do not have a circular cross-section, the $d_{e}$ is the diameter of a circle having an area equal to the average cross-sectional area of a fibre, calculated as

$d_{e}=\sqrt{\frac{400 m_{f}}{R D \pi l_{f(t)}}}$

where $m_{f}$ is the total mass of fibres in grams, $l_{f(t)}$ is the total length of the weighed fibres in $\mathrm{mm}$ (which is determined by multiplying the fibre length with the number of fibres) and RD is the relative density of the fibre (0.91 for polypropylene). In Table $1, l_{f}$ is the fibre length, $d_{e}(s)$ is the supplied $d_{e}$, $\lambda$ the aspect ratio $\left(l_{f} / d_{e}\right)$ and $\sigma_{f}$ is the supplied tensile strength. It should be noted that for tests conducted at the single-fibre level, longer fibre lengths obtained from the suppliers have been used to be able to study the effect of the various embedment lengths on the pull-out response.

\section{Concrete mix design}

The concrete mix constituents are CEM I $52.5 \mathrm{~N}$ cement with a relative density (RD) of 3.14, fine natural sand (known locally as Malmesbury sand) having an RD of 2.62, and a crushed Greywacke coarse aggregate (nominal size of $6 \mathrm{~mm}$ ) with an RD of 2.80 . Three concrete mixes (Mix 1, Mix 2, Mix 3), shown in Table 2, with water-cement ratios (w/c) of 0.6, 0.5 and 0.4 were used. The slump was measured in accordance with SANS 5862-1:2006 (SANS 2006a), and the compressive strength in accordance with SANS 5863-3:2006 (SANS 2006b) at an age of 28 days.

Concrete specimens were cast without fibres in the single-fibre pull-out test, except for the embedded single fibres that were added after the moulds had been filled. However, the effect of synthetic macro fibres on the compressive strength of concrete was investigated using Fibre 1 (at 0.5, 0.6, $0.7 \% \mathrm{vol}$ ), Fibre 3 (at $0.5,0.6,0.7 \% \mathrm{vol}$ ), Fibre 4 (at $0.3,0.5,0.6,0.7,0.9 \% \mathrm{vol}$ ) and Fibre 5 (at $0.6 \%$ vol). It should be noted that Fibre 1 is representative of Fibre 2, hence Fibre 2 was not tested for compressive strength. A close look at the fibre types (Table 1 and Figure 2) shows that the fibres can be grouped into three surface configurations:

Table 3 Fibre embedment lengths tested

\begin{tabular}{|c|c|c|c|c|}
\hline Embedment length $(\mathbf{m m})$ & Fibres $\mathbf{1} \mathbf{~ \& ~ 2}$ & Fibre 3 & Fibre 4 & Fibre 5 \\
\hline L1 & 10 & 12.5 & 12.5 & 12.5 \\
\hline L2 & 20 & 25.0 & 25.0 & 25.0 \\
\hline L3 & 30 & 37.5 & 37.5 & 37.5 \\
\hline L4 & 40 & 50.0 & 50.0 & 45.0 \\
\hline
\end{tabular}

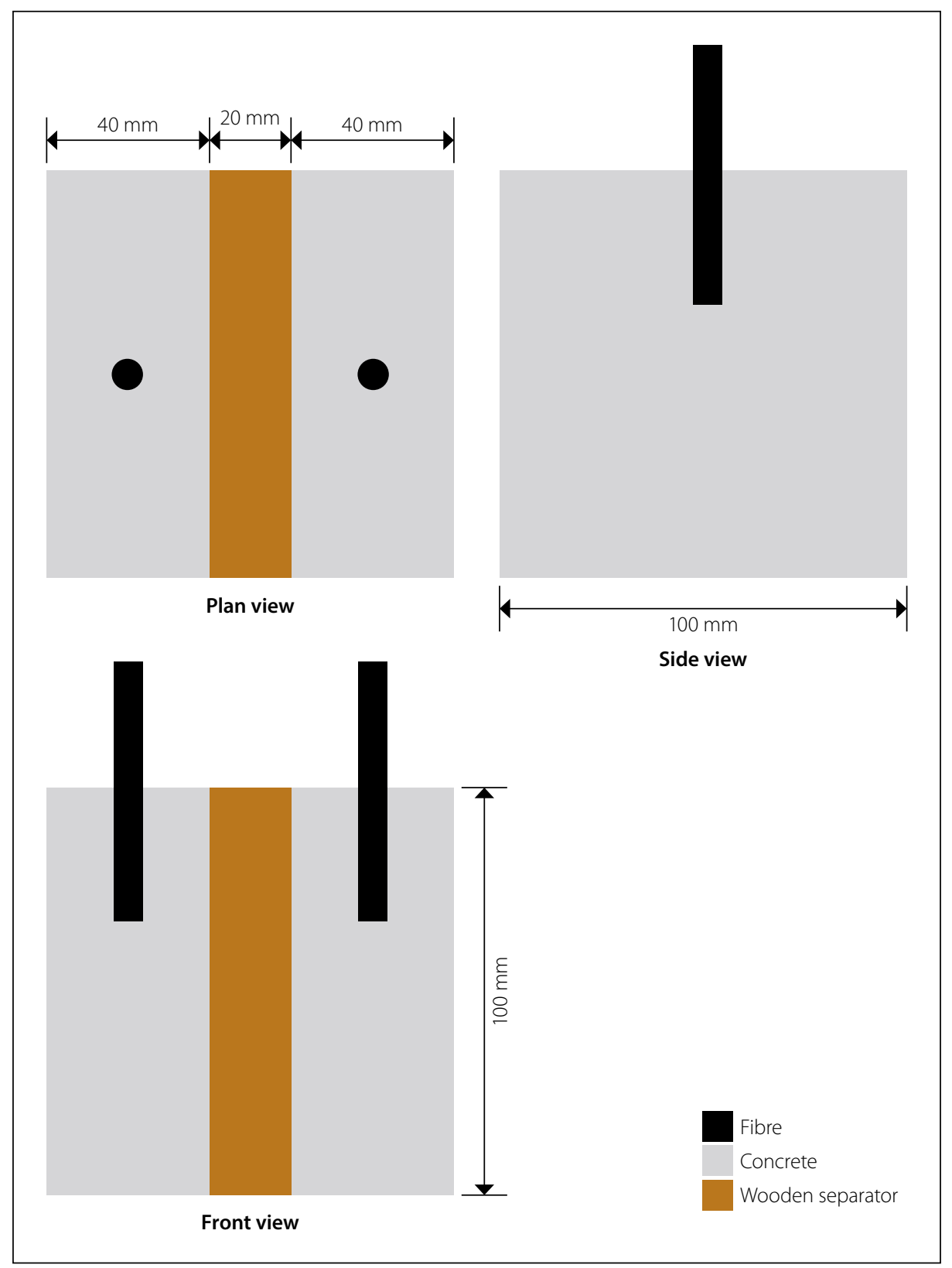

Figure 3 Schematics of single-fibre sample preparation (not to scale)

$\mathrm{X}$ cross-section and crimped (Fibres 1 and 2), oval cross-section and crimped (Fibre 3), and rectangular flat (Fibres 4 and 5). The fibre groupings were studied at $0.5 \%$, $0.6 \%$ and $0.7 \%$ volume, while two additional boundaries of low and high volumes $(0.3 \%$ \& $0.9 \%)$ were tested for the flat fibres.

\section{EXPERIMENTAL METHODS}

Single-fibre pull-out tests (SFPOT) were undertaken to study the pull-out behaviour of the fibres. Fibres 1 and 2 were tested at an embedment length of multiples of a third of its length, as well as a $40 \mathrm{~mm}$ fibre length. Fibres 1 and 2 were supplied in two different diameters and were thus used to investigate the effect of the diameter on the pull-out response. The effect of the variation in fibre diameter was only carried out for Mix 2 with w/c of 0.5. SFPOT for Fibres 3, 4 and 5 were performed at embedment lengths of multiples of a quarter of their lengths, as presented in Table 3 , 


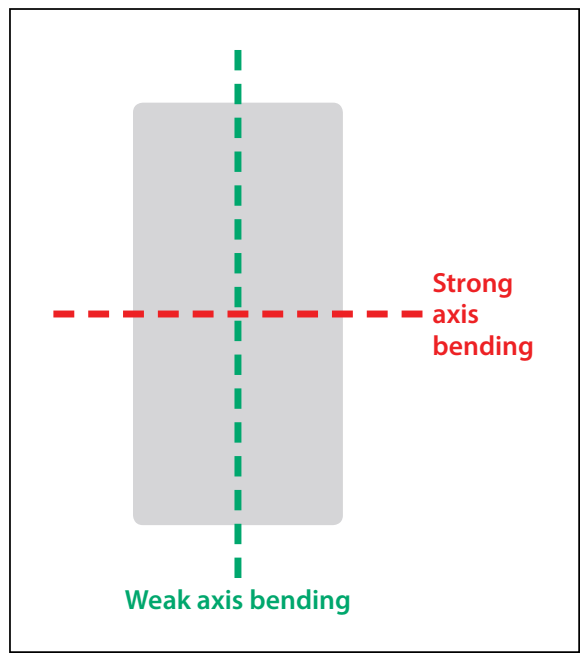

Figure 4 Cross-section of a flat rectangular fibre showing strong and weak axes

except for Fibre 5 where the final embedment length tested (L4) was $45 \mathrm{~mm}$.

Furthermore, the snubbing angle effect of these flexible fibres on the pull-out load was also investigated. Here only one embedment length was used for all fibres (two-thirds of the fibre length for Fibre 1, which is $20 \mathrm{~mm}$, and half the fibre length for the others, i.e. $25 \mathrm{~mm}$ ). Snubbing angles investigated were $0^{\circ}$ (i.e. perpendicular to the crack plane), $30^{\circ}$ and $60^{\circ}$. Only Mix 2 with a w/c of 0.5 was used to investigate the snubbing effect.

\section{Test specimen preparation}

For each fibre type, eight specimens, each measuring $100 \times 100 \times 40 \mathrm{~mm}^{3}$ were prepared and tested in the SFPOT. These specimens were obtained by dividing $100 \mathrm{~mm}$ polyvinyl chloride (PVC) cube moulds into

Table 4 Average compressive strength and slump values

\begin{tabular}{|c|c|c|c|c|}
\hline Mix & $w / c$ & $\begin{array}{l}\text { Compressive } \\
\text { strength } \\
\text { (MPa) }\end{array}$ & $\begin{array}{l}\text { CoV } \\
(\%)\end{array}$ & $\begin{array}{l}\text { Slump } \\
(\mathrm{mm})\end{array}$ \\
\hline Mix 1 & 0.4 & 59.0 & 4 & 70 \\
\hline Mix 2 & 0.5 & 52.2 & 3 & 150 \\
\hline Mix 3 & 0.6 & 43.1 & 7 & 200 \\
\hline
\end{tabular}

two halves with wooden blocks, resulting in two specimens per cube mould, as shown in Figure 3 on page 23. The dry mix constituents without fibres were mixed for about three minutes before the addition of water.

After mixing, the fresh concrete was cast in the moulds and vibrated on a vibrating table. The fibres were then inserted into the centre of the fresh concrete up to the pre-marked embedment lengths. For the less flexural stiff fibres (Fibres 4 and 5), one of the flexural stiff fibres (Fibre 1) was initially used to create the openings before the less flexural stiff fibres were inserted to the desired embedment length. The reason for the difference in flexural stiffness is the different cross sections of the fibres. After the insertion, moulds were gently vibrated to close the voids created between the fibre and the concrete. The samples were allowed to set in a temperature-controlled chamber at $23^{\circ} \mathrm{C}$ for $24 \mathrm{~h}$, and then submerged in a curing tank at $22^{\circ} \mathrm{C}$ until testing at 28 days.

For the evaluation of the snubbing effect, the fibres were inserted at the snubbing angles previously mentioned. The flat fibres were inserted at a specific orientation to ensure bending about their strong axis during pull-out, as shown in Figure 4.

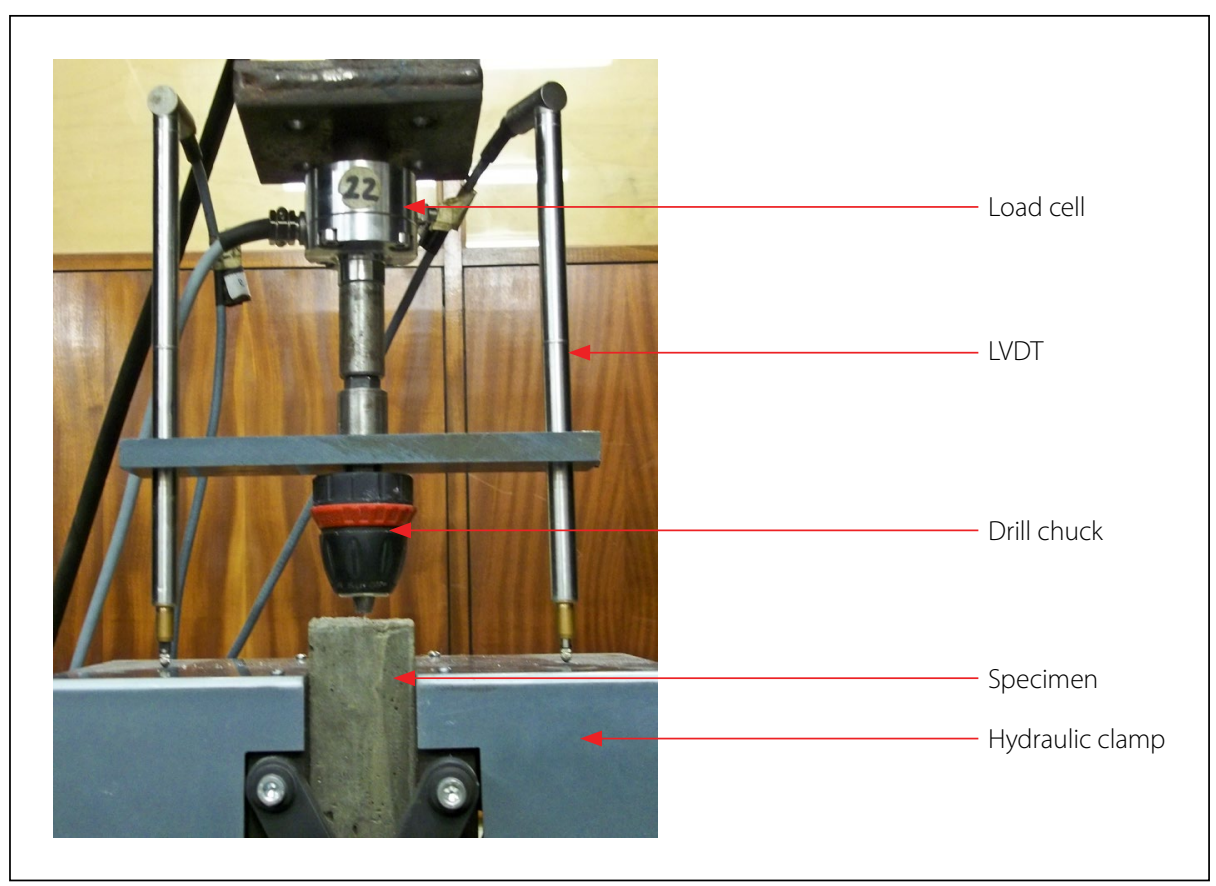

Figure 5 Single-fibre pull-out test setup

\section{Test setup for SFPOT}

The SFPOT setup is shown in Figure 5. The tests were performed in a Zwick Z250 Universal Testing Machine. Hydraulic clamps held the bottom part of the concrete specimen. The fibre clamp gripped the fibre protruding from the concrete, as close as possible to the concrete surface to minimise the effect of fibre elongation. Two $50 \mathrm{~mm}$ HBM linear variable differential transformers (LVDTs) were used to measure pull-out displacement. The HBM load cell used has a capacity of $250 \mathrm{~kg}$. The pull-out tests were performed at a constant crosshead displacement rate of $0.2 \mathrm{~mm} / \mathrm{s}$.

A drill chuck shown in Figure 5 was used as a fibre clamp for the non-flat Fibres 1 and 2. The drill chuck was unable to grip the flat Fibres 4 and 5 without slippage, hence a separate clamp was manufactured for gripping these fibres.

This clamp consisted of two flat metal parts clamping the fibre as shown in Figure 6. A permanent marker was used to mark the fibres at the clamp-fibre interface to help identify fibre slippage. If fibre slippage was observed at the clamped section, the results of such tests were discarded.

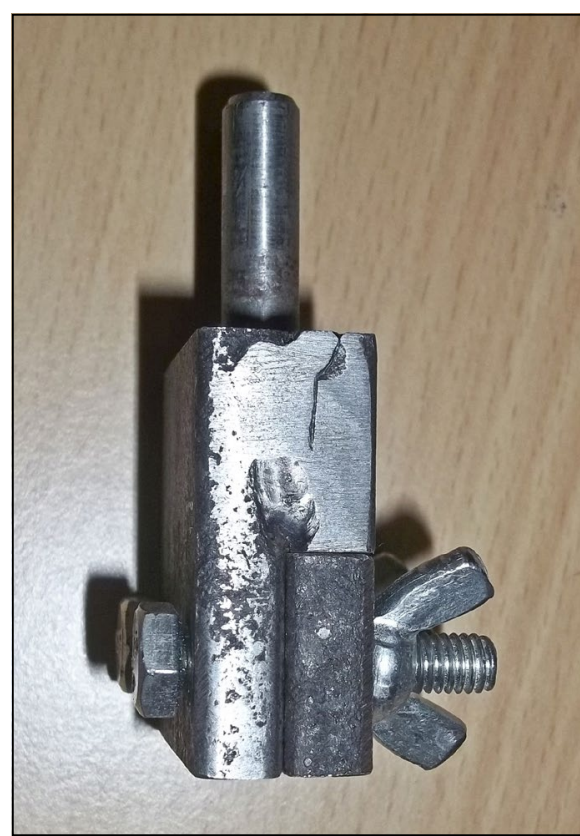

Figure 6 Clamp developed and used for flat fibres 


\section{RESULTS AND DISCUSSION}

\section{Compressive strength}

The results of the compressive strength and slump tests of mixes without fibres are presented in Table 4, with the coefficient of variation $(\mathrm{CoV})$ of the compressive strength shown.

As expected, the compressive strength of the mixes increases as the w/c decreases, whereas the slump increases as the $\mathrm{w} / \mathrm{c}$ increases. The effect of adding fibres on the compressive strength of Mix 3 is shown for the four different fibres in Figure 7. Only Fibre 4 was tested at 0.3 and $0.9 \%$ dosages, while Fibre 5 was only tested at $0.6 \%$ dosage. Figure 7 reveals that the addition of the fibres has a negative effect on the compressive strength of the concrete at the dosages investigated. This is consistent with several works on the effect of synthetic fibres on the compressive strength of ordinary concrete (Hsie et al 2008; Babafemi \& Boshoff 2015).

The crimped fibre (Fibre 3) shows an increase in compressive strength from the 0.5 to $0.7 \%$ dosages, even attaining the strength of the control at $0.7 \%$ fibre dosage. For the slightly crimped (Fibre 1) and the flat (Fibre 4) no particular trend is apparent. At $0.6 \%$ fibre dosage, all fibres resulted in a lower compressive strength compared to the control, with Fibre 1 showing the most severe reduction. The reduction in compressive strength of concrete due to the addition of fibres is attributed to the increased voids created during mixing and the nonhomogeneity in the microstructure due to the distribution of fibres within the matrix.

\section{Pull-out behaviour of synthetic macro fibres}

All results presented here are the average of the maximum pull-out load for each set of fibre type and embedment length. This value is typically at the onset of pull-out and gradually drops until complete pull-out is achieved. A typical pull-out response for each fibre type is shown in Figure 8.

\section{Fibres 1 and 2}

The average maximum pull-out loads of Fibre 1 at different embedment lengths and w/c are shown in Figure 9. Also shown is the response of Fibre 2, which is the same as Fibre 1 except for a smaller equivalent diameter at different embedment lengths, and a w/c of 0.5 .

One significant factor that influences the average maximum pull-out loads, as

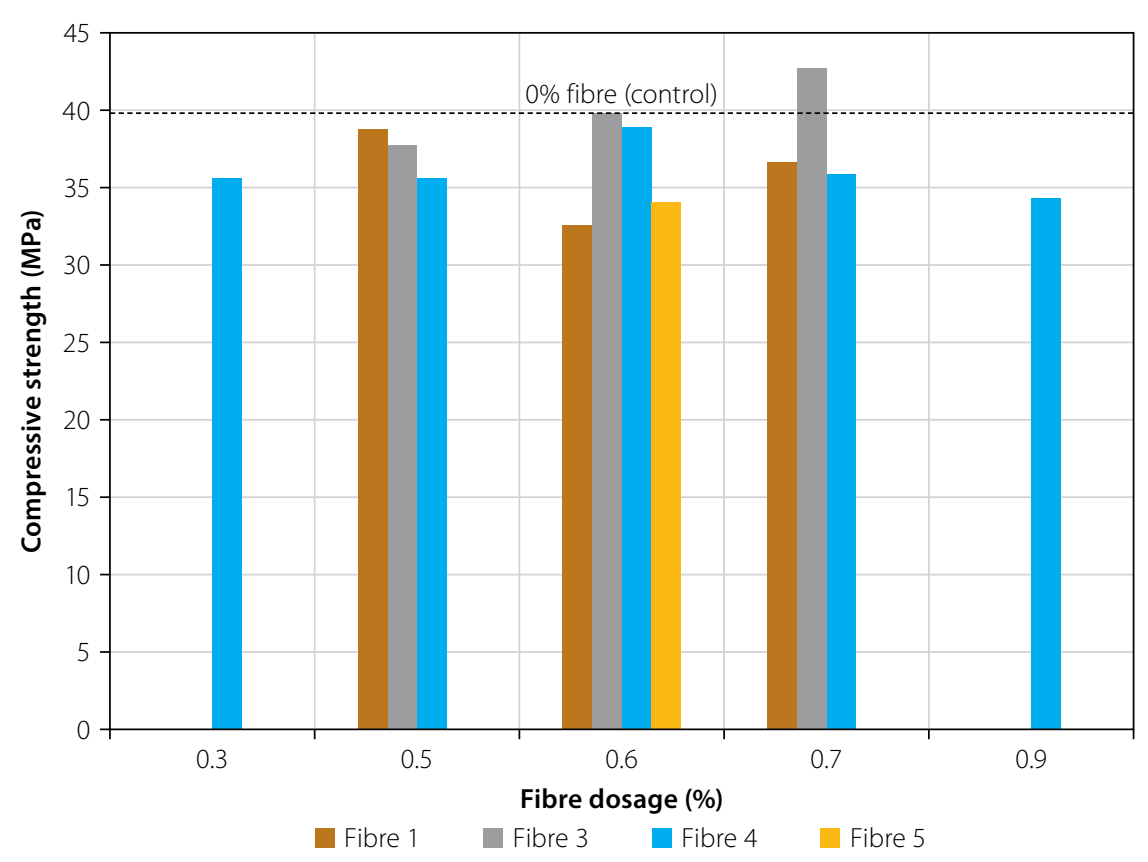

Figure 7 Influence of fibre type and dosage on compressive strength of concrete

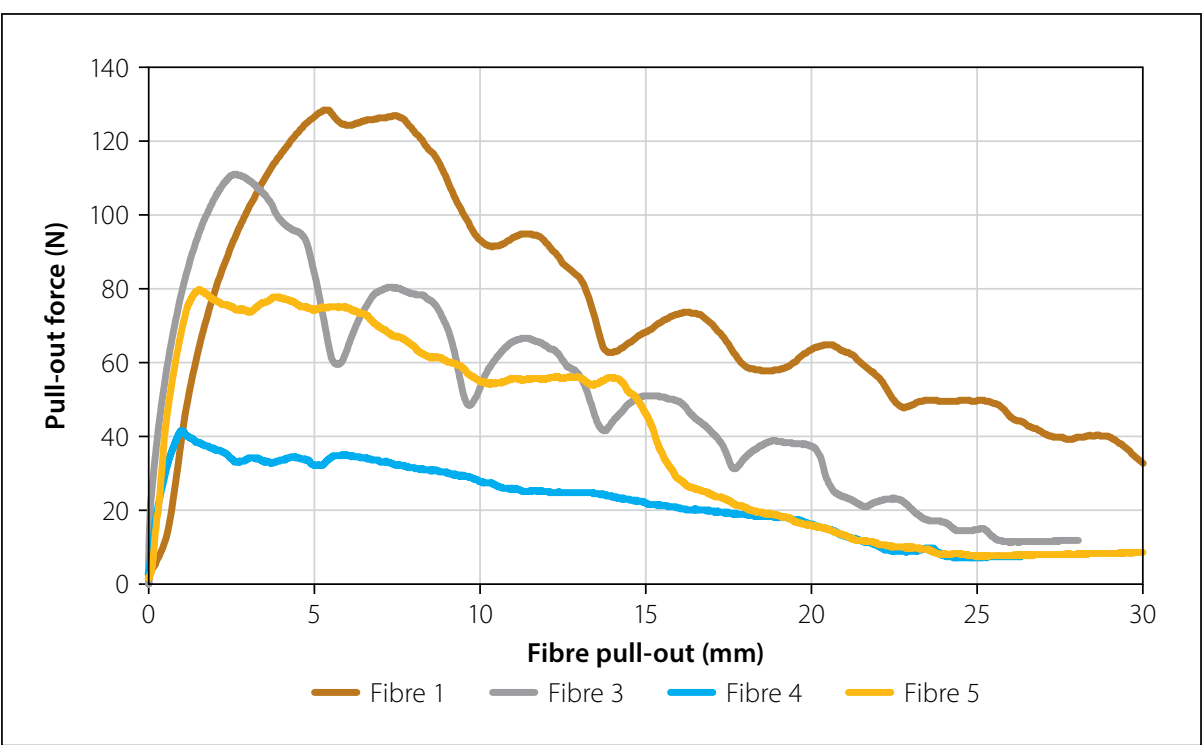

Figure 8 Typical pull-out responses of each fibre type

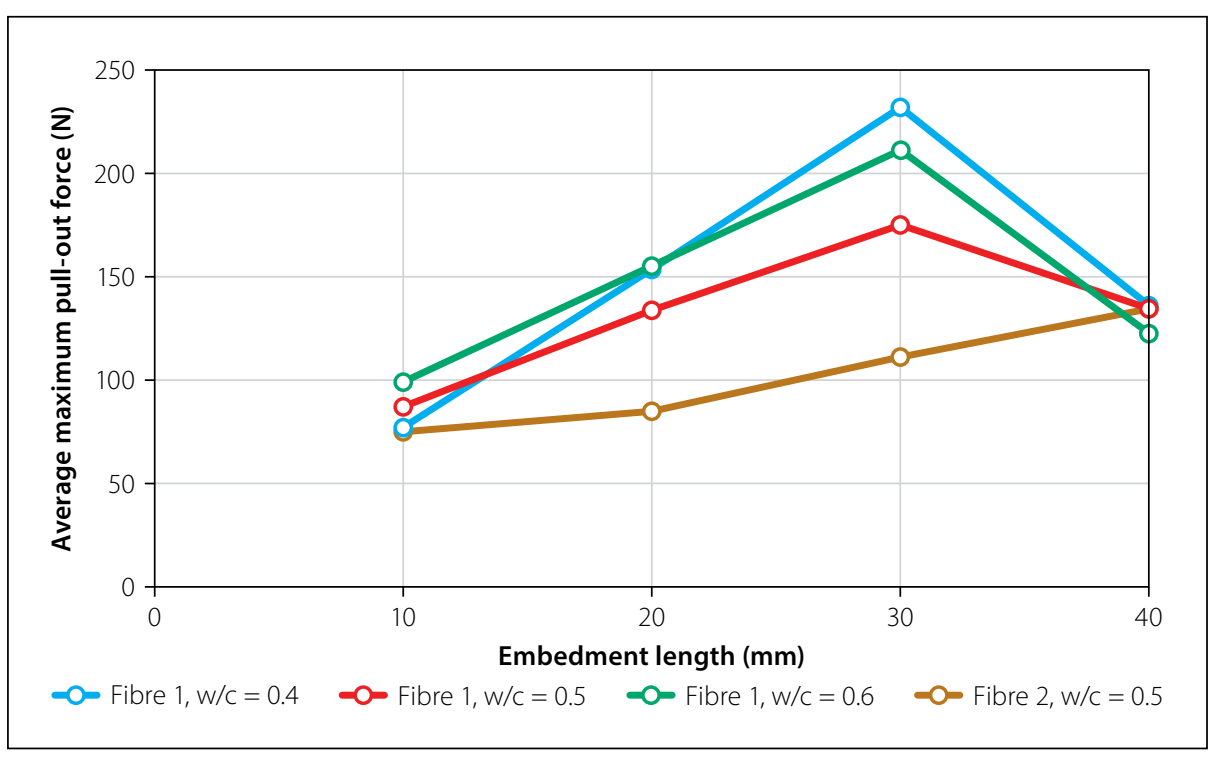

Figure 9 Average pull-out loads of Fibres 1 and 2 at different embedment lengths and w/c 


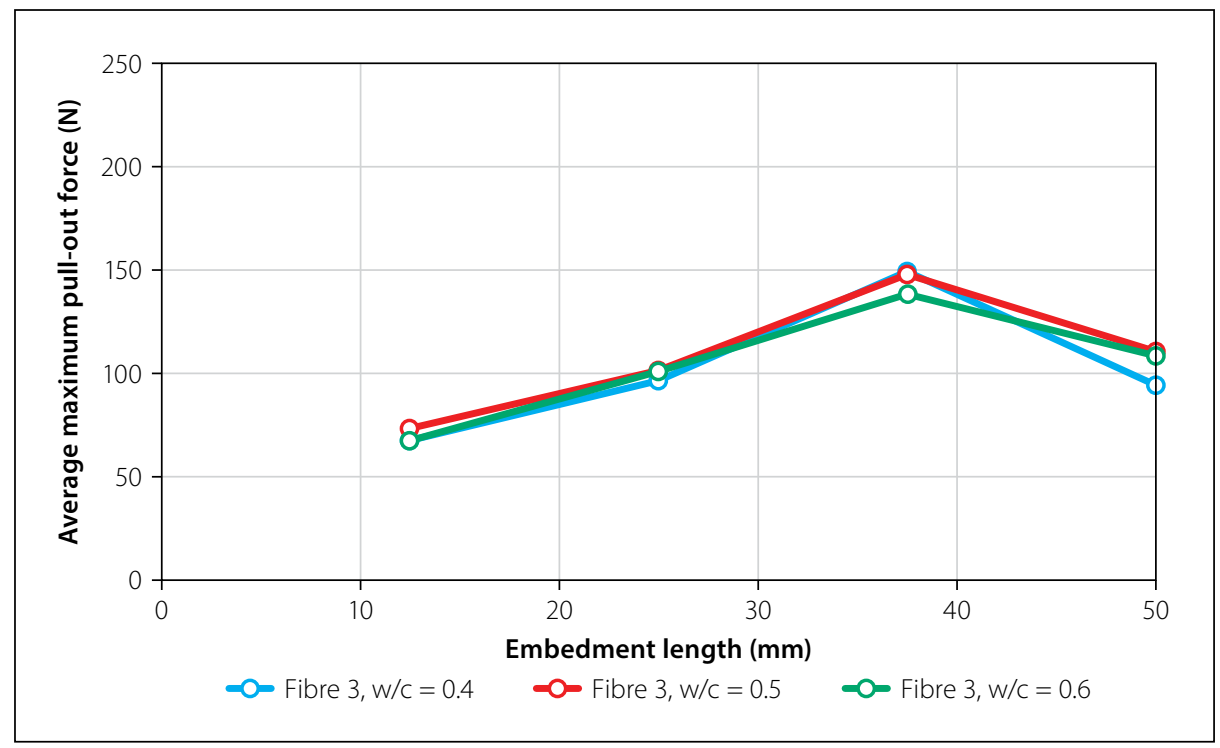

Figure 10 Average pull-out loads of Fibre 3 at different embedment lengths and w/c

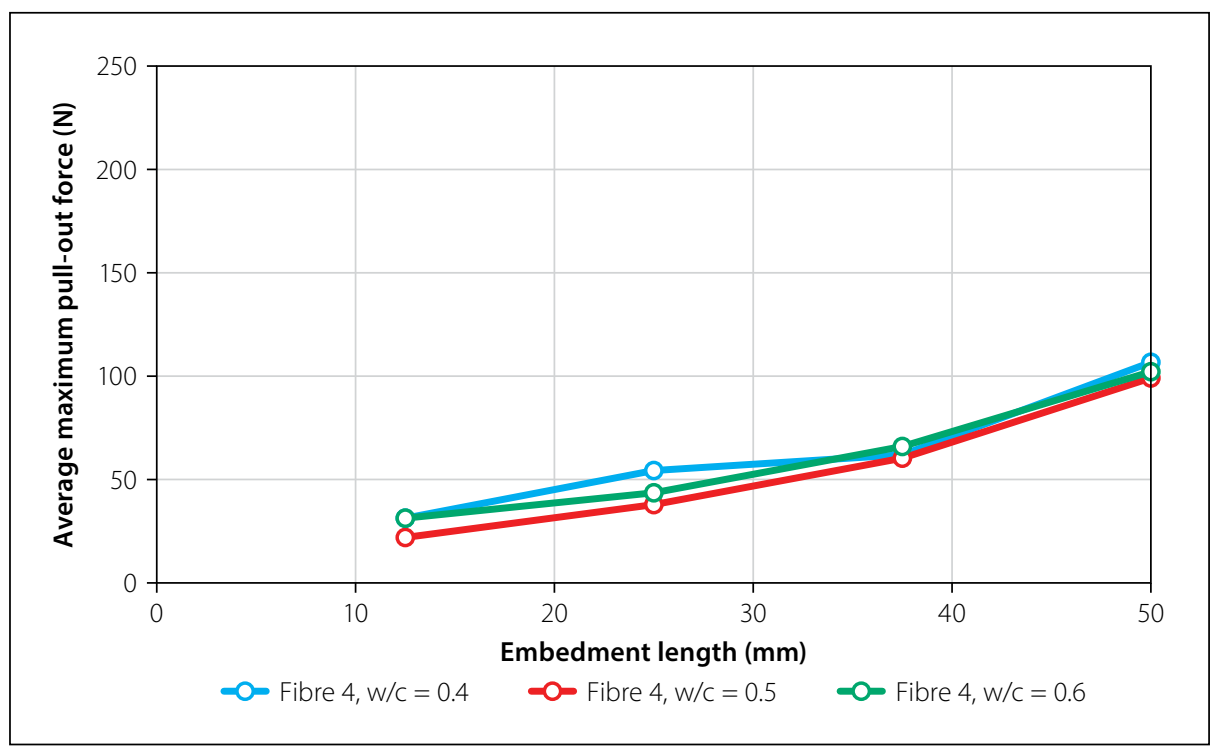

Figure 11 Average pull-out loads of Fibre 4 at different embedment lengths and w/c

can be seen in Figure 9, is the fibre diameter. With a $40 \mathrm{~mm}$ embedment length, a significant drop in the average maximum pull-out load is observed. It should be mentioned that the fibres with $40 \mathrm{~mm}$ embedment lengths had an equivalent diameter similar to Fibre 2 which is less than Fibre 1, which explains the drop in the average maximum pull-out load at this embedment length. Similarly, Fibre 2 with the lesser equivalent diameter showed a significantly lower maximum pull-out load compared to Fibre 1 at embedment lengths of $20 \mathrm{~mm}$ and $30 \mathrm{~mm}$. This indicates that the average maximum pull-out load is a function of the equivalent diameter of the fibre. However, the effect of the equivalent diameter for the flat fibres still needs to be researched. The w/c showed no effect on the pull-out response. Figure 9 did show some effect of the w/c, but this is not significant as the highest and lowest w/c showed almost the same behaviour, which is not expected if the w/c did have a significant effect.

The results indicate that with the increase in the fibre embedment length, the higher the average maximum pull-out load will be at various w/c. The increase in the average maximum pull-out load as the fibre length increases for this type of fibre has also been reported elsewhere (Babafemi \& Boshoff 2017).

\section{Fibre 3}

The effect of embedment length and w/c on the average maximum pull-out load of Fibre 3 is shown in Figure 10. Fibre 3 shows that the pull-out performance is not a function of the w/c, as all performed similarly at different w/c. In addition, the average maximum pull-out load also increases with increasing embedment length.

In Figure 10, beyond an embedment length of $37.5 \mathrm{~mm}$, a drop in the average maximum pull-out load can be observed. It should be mentioned that, from a physical observation of the $50 \mathrm{~mm}$ fibres, they showed a less pronounced crimped configuration (lower amplitude) compared to the shorter fibres. It is believed that the drop in the average maximum pull-out load at this embedment length is due to the lower amplitude of the fibre. Bentur et al (1997) and Won et al (2006) also showed that the amplitude of a polymeric fibre has an effect on the average maximum pull-out load. All lengths of Fibre 3 have the same equivalent diameter, hence the effect of equivalent fibre diameter plays no role in the observed drop at $50 \mathrm{~mm}$ as explained for Fibre 1.

\section{Fibre 4}

The pull-out performance of Fibre 4, which has a flat longitudinal geometry, is also not influenced by the w/c, while the average maximum pull-out load also increases with an increase in embedment length, as shown in Figure 11. The average maximum pullout load is much lower than for Fibres 1, 2 and 3 . This suggests that the fibre geometry is an important factor in the pull-out performance of synthetic macro fibre when used in concrete. However, increase in the average maximum pull-out load can be observed up to a fibre embedment length of $50 \mathrm{~mm}$. The near linear average maximum pull-out load to embedment length relationship observed for Fibre 4 indicates that the critical fibre length was not embedded in the matrix as only a few specimens experienced fracture. The critical fibre length is the length for which a shorter length would result in no fibre rupture and a larger length would result in significant fibre rupture during mechanical testing. The critical fibre length is double the critical embedment length, as determined using single-fibre pull-out tests. Using the critical length for fibres will result in the optimal behaviour.

\section{Fibre 5}

The average maximum pull-out load of Fibre 5, as with all other synthetic macro fibres, is dependent on the embedment length, with no visible effect of w/c, as shown in Figure 12. It can be concluded that the average maximum pull-out load of synthetic macro fibres is not dependent on w/c ranging from 0.4 to 0.6 . The average maximum pull-out load for Fibre 5 is $111 \mathrm{~N}$, which is similar to the pull-out performance of Fibre 4 that also has a flat geometry.

A near linear increase in average maximum pull-out load with increasing 
embedment length occurred up to around $37.5 \mathrm{~mm}$, where fibres fractured. At embedment lengths of $45 \mathrm{~mm}$, all but two of the fibres fractured across all w/c investigated. The average maximum pull-out loads appears to plateau at around $110 \mathrm{~N}$.

Figure 13 shows the percentage of fibres that fractured for all fibres tested at different embedment length. During the pull-out test of Fibre 1, complete fibre pull-out was recorded up to an embedment length of $30 \mathrm{~mm}$. It should be noted that Fibre 1 (with the greater $d_{e}$ ) was only tested up to $30 \mathrm{~mm}$ embedment length as previously described, as the $40 \mathrm{~mm}$ embedment length had a smaller $d_{e}$. However, the $40 \mathrm{~mm}$ embedded fibres of Fibre 1 with a smaller $d_{e}$ showed a fracture of $50 \%$ (Figure 12). Meanwhile, complete pull-out was only recorded at an embedment length of $10 \mathrm{~mm}$ for Fibre 2 (with the lesser $d_{e}$ ). At $20 \mathrm{~mm}$ embedment length for Fibre 2, fracture was about 17\%, while at $40 \mathrm{~mm}$ embedment lengths, about $54 \%$ fractured during pull-out. The result of the percentage fracture at an embedment length of $40 \mathrm{~mm}$ for the fibres with lesser $d_{e}$ grouped with Fibre 1, agrees much better with similar fibres classified as Fibre 2 at the same embedment length. These results indicate that the critical fibre length (length at which fracture occurs) is a function of the equivalent fibre diameter for the crimped fibres tested. Thus, if a significant portion of fibre fractures at a particular embedment length, i.e more than $10 \%$, it indicates that the critical embedment length was reached between the previous embedment length and the current embedment length.

Less than $40 \%$ fracture occurred for Fibre 3 at 37.5 and $50 \mathrm{~mm}$, while less than $10 \%$ occurred at 37.5 and $50 \mathrm{~mm}$ for Fibre 4, and about $90 \%$ at 37.5 and $45 \mathrm{~mm}$ for Fibre 5. It can be inferred that the embedment lengths at which the peak percentage of fractures occur is an indication of the critical fibre length. Fibre pull-out is the preferred failure mechanism rather than fibre rupture, as pull-out results in a ductile failure, with the fibre pull-out process absorbing more energy than a fibre rupture. The critical fibre length is twice the critical embedment length, as the shortest embedment length is dominant when a fibre crosses a crack plane in concrete. It is important to note that the fibre fracture did not occur at the fibre's clamping point. For samples where fracture occurred at the clamp, the results were discarded. Evidently, the fibres that pulled out completely show that the pull-out stress did

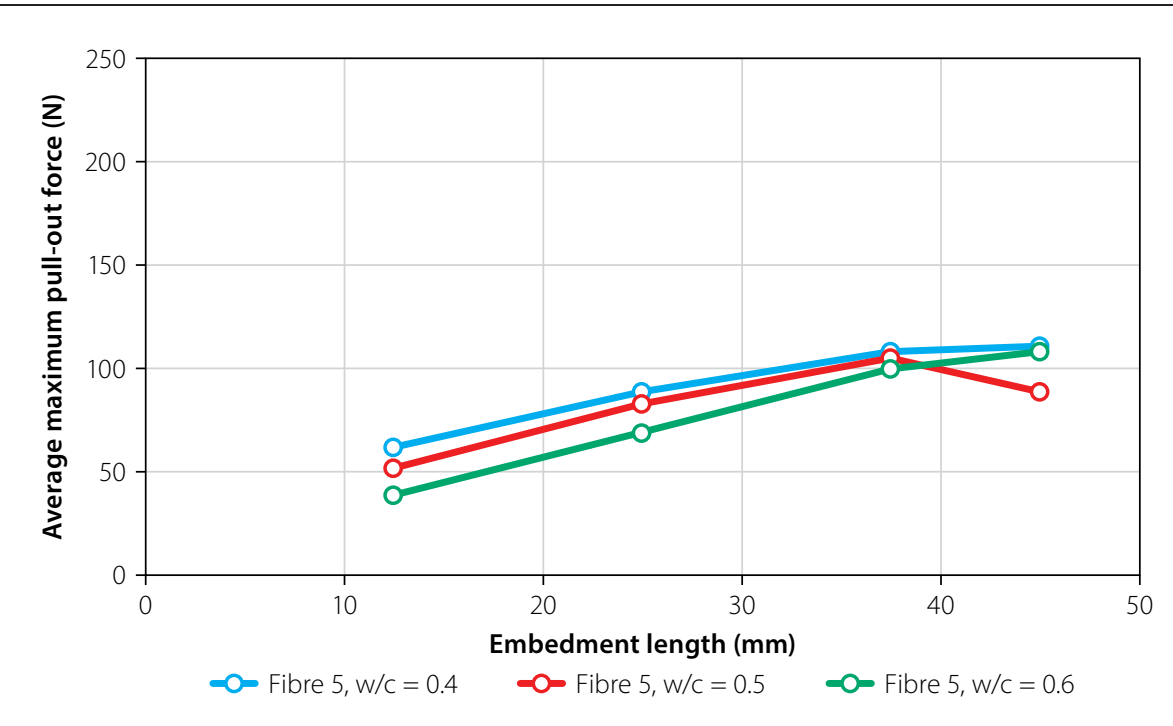

Figure 12 Average pull-out loads of Fibre 5 at various embedment lengths and w/c

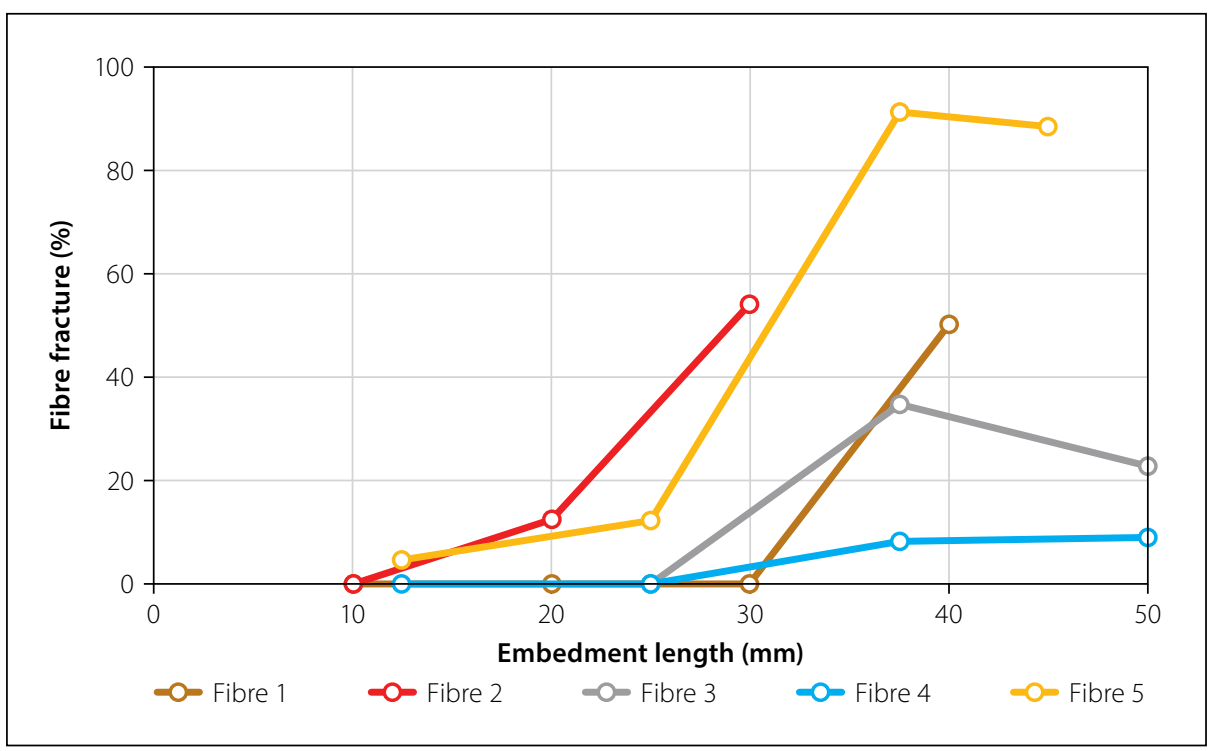

Figure 13 Percentage of fibre fractures at different embedment lengths

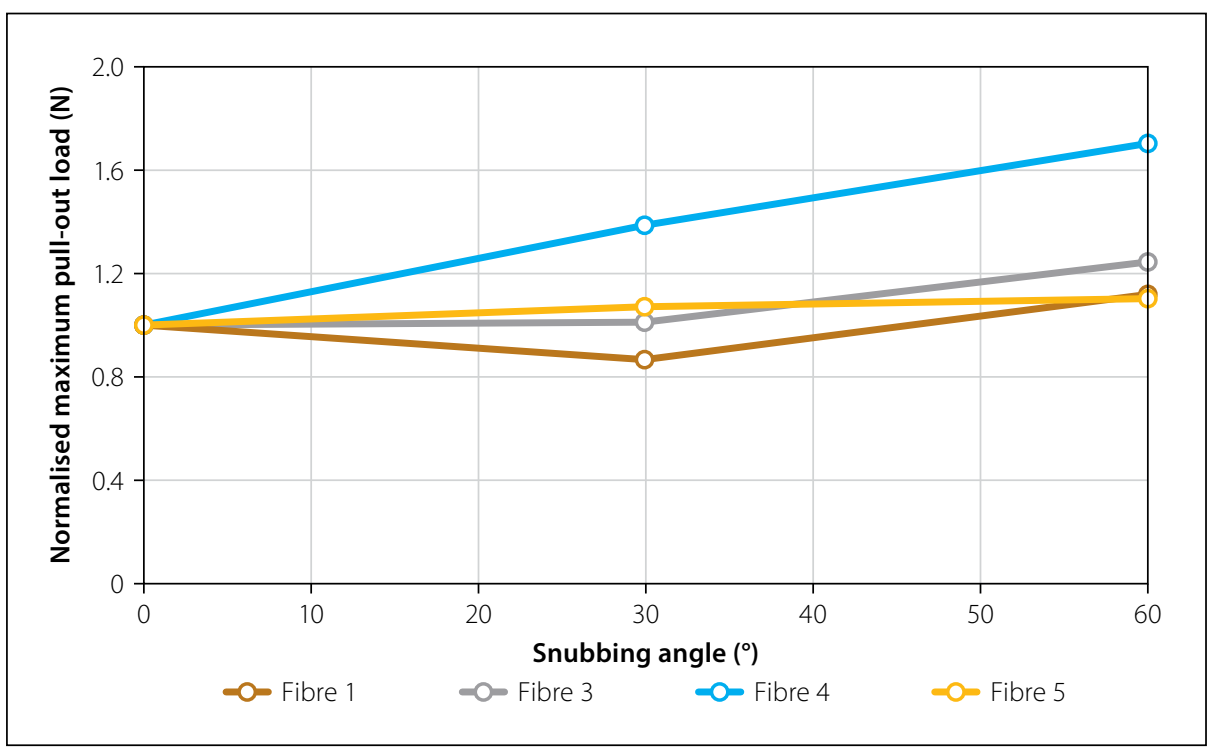

Figure 14 Snubbing effect on pull-out load of synthetic macro fibres

not exceed the fibre's stress. On the other hand, the fracture fibres show that the fibre stress is exceeded during pull-out.
It is common knowledge that the w/c influences the compressive strength of concrete. The lower the w/c, the higher 
the compressive strength. This, however, does not influence the fibre/matrix interface, and is believed to be due to the hydrophobic nature of the polypropylene fibres. The poor bonding is enhanced by the fibre geometry rather than the concrete strength, which is dependent on the w/c. In fact, the maximum fibre/matrix bond strength has been reported to be attained just within the first two days (Singh et al 2004), unlike the compressive strength that continues to increase with age. Therefore the w/c does not influence the maximum bond load, rather, the maximum bond load is a function of the properties of the fibre.

\section{Effect of snubbing angle on pull-out load}

The orientation of fibres influence the pullout performance of cement composites.

Figure 14 shows the normalised plot of the average maximum pull-out load against the snubbing angles of all fibres tested. All the fibres had an embedment length of $25 \mathrm{~mm}$, except Fibre 1 which was embedded at $20 \mathrm{~mm}$. The purpose of these tests is to evaluate the effect of snubbing for different fibres, therefore this small change in embedment length for the one fibre is believed to be insignificant.

As the results were normalised to the pull-out resistance of each fibre type at $0^{\circ}$, they all start at 1.0 . At $30^{\circ}$ and $60^{\circ}$ differences can be seen for the various fibres, indicating increased frictional effect at these angles. Fibre 4 experienced a 39\% and 70\% increase in the average maximum pull-out loads at $30^{\circ}$ and $60^{\circ}$ respectively. As mentioned, the bending of the fibre was about its strong axis, as shown in Figure 3. If the fibre is considered as a beam subjected to flexural bending, bending the fibre about its strong axis requires a larger force than for bending it to the same rotation about the weak axis. This could subsequently lead to a larger friction over a constant area for strong axis bending as opposed to weak axis bending. In addition, strong axis bending is exerted over a smaller area, which is believed will lead to a larger frictional stress. As the increase in the snubbing angle causes an increase in the frictional force over a constant surface area, a larger increase in the overall pull-out load contribution is believed to occur.

Fibre 5 experienced a $7 \%$ and $10 \%$ pullout load increase at $30^{\circ}$ and $60^{\circ}$, respectively. This plateau can be attributed to the fibres rupturing when the tensile strength of the fibres is exceeded due to the additional

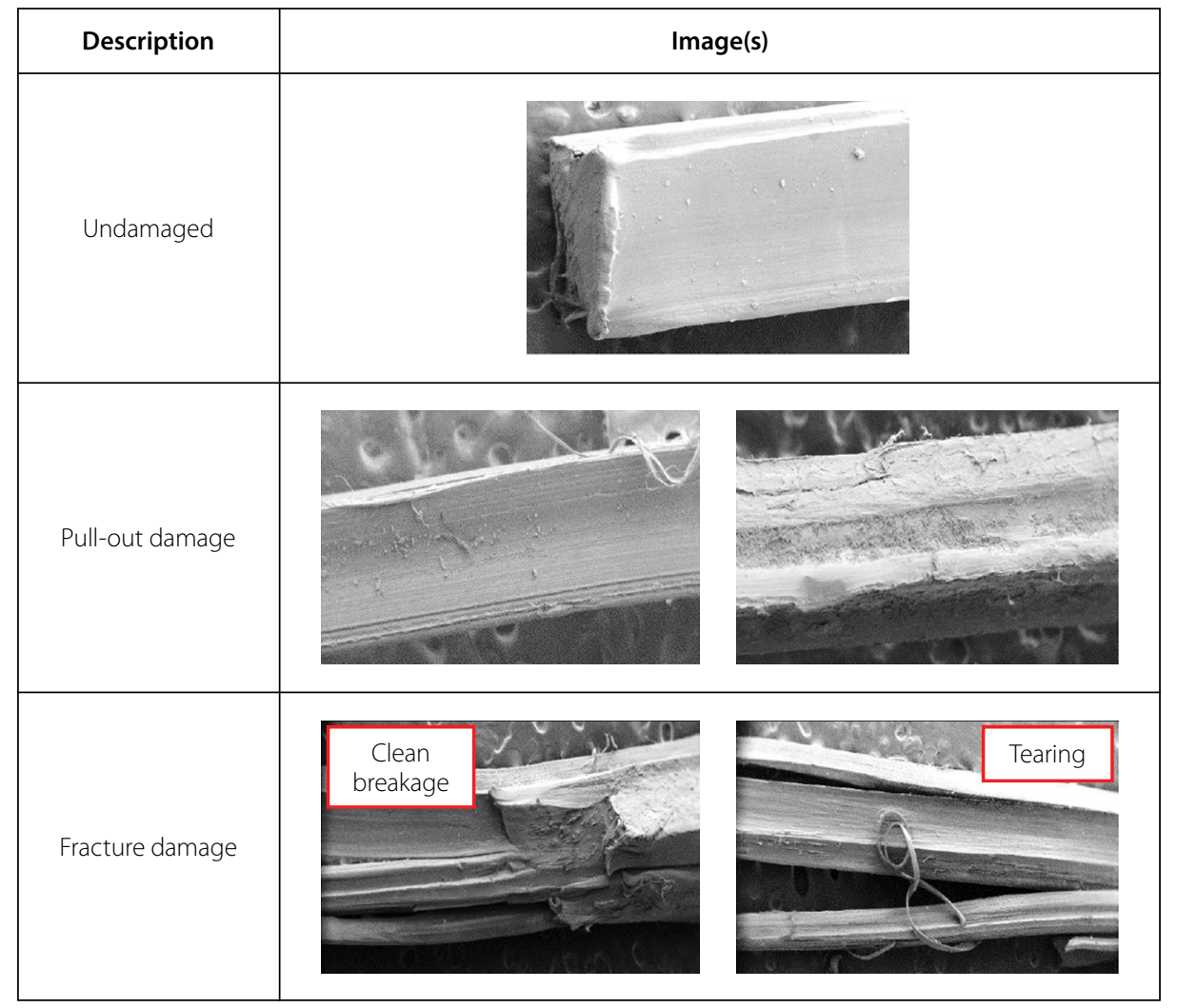

Figure 15 SEM images of Fibre 1 before and after pull-out

\begin{tabular}{|c|c|c|}
\hline Description & Image(s) \\
\hline $\begin{array}{c}\text { Undamaged } \\
\text { Pull-out damage } \\
\text { (middle and } \\
\text { end) }\end{array}$ & $\begin{array}{c}\text { Fracture damage } \\
\text { Pull-out damage } \\
\text { (interface) }\end{array}$ \\
\hline
\end{tabular}

Figure 16 SEM images of Fibre 3 before and after pull-out 


\begin{tabular}{|l|c|c|}
\hline Description & Image(s) \\
\hline Undamaged & & \\
\hline $\begin{array}{c}\text { Pull-out damage } \\
\text { (middle and } \\
\text { end) }\end{array}$ & & \\
\hline
\end{tabular}

Figure 17 SEM images of Fibre 4 before and after pull-out

\begin{tabular}{|l|l|}
\hline Description & Image(s) \\
\hline Undamaged &
\end{tabular}

Figure 18 SEM images of Fibre 5 before and after pull-out

resisting force offered by the frictional snubbing resistance. This is confirmed by six of the eight fibres fracturing at the cement-matrix surface at the $60^{\circ}$ snubbing angle. While the crimped Fibre 3 showed a $25 \%$ increase at $60^{\circ}$ snubbing angle, Fibre 1 showed an increase of $11 \%$ at $60^{\circ}$. At $30^{\circ}$, Fibre 1 showed a decrease in pull-out load of $13 \%$ before increasing again at $60^{\circ}$. This is likely due to inconsistent orientation of the cross-sectional axis which the fibre was bent about. Overall, the flat fibres performed better than the crimped fibres at the snubbing angles considered.

\section{SEM photos of pulled out fibres}

Scanning Electron Microscope (SEM) images were taken for each type of fibre to study the effect of friction during the pullout testing. Fibre 1 showed pronounced surface damage that can be attributed to its $\mathrm{X}$-shaped cross section, hence enhancing bonding between the fibre and matrix. Fibre fracture of Fibre 1 appears to be a combination of clean breakage and tearing, as shown in Figure 15.

Fibre 3 shows severe fibre damage caused by the scraping of the cement matrix against the fibre during pull-out, as shown in Figure 16. Variable damage can be observed at different portions of the fibre. Significantly less damage at the cement matrix interface or surface can be observed as opposed to the images at the middle of the fibre and at the embedded ends. The increased damage is due to the embedded end having to travel further to exit the cement matrix, resulting in more scrapings. The fracture mode for Fibre 3 appears to be fibre splitting.

Fibre 4, which showed the lowest average maximum pull-out load, also showed minimal surface damage, as shown in Figure 17. This is due to the flat geometry of the fibre.

Severe scrapings after pull-out were also observed for Fibre 5 as shown in Figure 18. However, the damage is more than observed for Fibre 4, indicating better bond than Fibre 4. This is also reflected by the average maximum pull-out load obtained in the single-fibre pull-out tests. Fibre 5 also tends to fibrillate after pull-out.

\section{CONCLUSIONS}

The pull-out performance of four locally available synthetic macro fibres was determined using single-fibre pull-out tests. The effect of these fibres on the compressive strength was also tested. The following conclusions can be drawn from this study:

- Synthetic macro fibres do not contribute to the compressive strength of concrete.

- The pull-out performance of synthetic macro fibres in a single pull-out test is not a function of w/c.

- The fibre diameter does influence the average maximum pull-out load. Fibres with greater equivalent diameter show higher pull-out loads for the fibres tested. More work is required to determine similar trends for other types of fibres.

- The average maximum pull-out load of synthetic macro fibres increases as the embedment length increases, while fibre geometry has a significant influence.

- The average maximum pull-out load of synthetic macro fibres is positively influenced with an increase in the snubbing 
angle, where in addition flat fibres perform better than crimped fibres.

- Fibre 1 performed optimally in terms of the average maximum pull-out load attained. This is due to its crimped surface configuration and $\mathrm{X}$-shaped cross section, which enhanced mechanical interlocking with the matrix.

- The Scanning Electron Microscope images of fibres taken after pull-out show that fibre geometry has an effect on the maximum pull-out load. The more irregular the fibre geometry, the more the frictional effect during pullout leading to higher pull-out load.

\section{REFERENCES}

Alani, A M, Beckett, D 2013. Mechanical properties of a large-scale synthetic fibre reinforced concrete ground slab. Construction and Building Materials, 41: 335-344.

Babafemi, A J \& Boshoff, W P 2015. Tensile creep of macro-synthetic fibre reinforced concrete (MSFRC) under uni-axial tensile loading. Cement and Concrete Composites, 55: 62-69.

Babafemi, A J \& Boshoff, W P 2017. Pull-out response of macro synthetic fibre from concrete matrix: Effect of loading rate and embedment length. Construction and Building Materials, 135: 590-599.

Bentur, A, Peled, A \& Yankelevsky, D 1997. Enhanced bonding of low modulus polymer fibers-cement matrix by means of crimped geometry. Cement and Concrete Research, 27(7): 1099-1111.

Bernard, E S 2004. Creep of cracked fibre reinforced shotcrete panels. Proceedings, 2nd International
Conference on Engineering Developments in Shotcrete (Shotcrete: More Engineering Developments), 47-57.

Boshoff, W P \& Combrinck, R 2013. Modelling the severity of plastic shrinkage cracking in concrete. Cement and Concrete Research, 48: 34-39.

Buratti, N, Mazzotti, C \& Savoia, M 2011. Postcracking behaviour of steel and macro-synthetic fibre-reinforced concretes. Construction and Building Materials, 25(5): 2713-2722.

Concrete Society 2014. Concrete Industrial Ground Floors. A Guide to Design and Construction, 4th ed. Technical Report 34, Camberley, UK: The Concrete Society.

De la Fuente, A, Escariz, R C, de Figueiredo, A D \& Aguado, A 2013. Design of macro-synthetic fibre reinforced concrete pipes. Construction and Building Materials, 43: 523-532.

EN (European Standard) 2006. BS EN 14889-2:2006. Fibres for concrete. Polymer fibres. Definitions, specifications and conformity. London: British Standards Institution.

Ferrara, L \& Meda, A 2006. Relationships between fibre distribution, workability and the mechanical properties of SFRC applied to precast roof elements. Materials and Structures, 39(4): 411-420.

Hannant, D J 1998. Durability of polypropylene fibers in Portland cement-based composites: Eighteen years of data. Cement and Concrete Research, 28(12): 1809-1817.

Hsie, M, Tu, C \& Song. P S 2008. Mechanical properties of polypropylene hybrid fiber reinforced concrete. Materials Science and Engineering. A. Structures, 494(1-2): 153-157.

Lie, T T \& Kodur, V K 1996. Thermal and mechanical properties of steel-fibre-reinforced concrete at elevated temperatures. Canadian Journal of Civil Engineering, 23(2): 511-517.

Mindess, S \& Zhang, L 2009. Impact resistance of fibre-reinforced concrete. Proceedings of the Institution of Civil Engineers - Structures and Buildings, 162(1): 69-76.

Pujadas, P, Blanco, A, Cavalaro, S, de la Fuente A \& Aguado, A 2017. The need to consider flexural postcracking creep behavior of macro-synthetic fiber reinforced concrete. Construction and Building Materials, 149(15): 790-800.

Richardson, A E 2005. Bond characteristics of structural polypropylene fibres in concrete with regard to post-crack strength and durable design. Structural Survey, 23(3): 210-230.

Singh, S, Shukla, A \& Brown, R 2004. Pullout behaviour of polypropylene fibers from cementitious matrix. Cement and Concrete Research, 34: 1919-25.

Sorelli, L G, Meda, A \& Plizzari, G A 2006. Steel fiber concrete slabs on ground: A structural matter. ACI Structural Journal, 103(4): 551-558.

SANS (South African National Standard) 2006a. SANS 5862-1:2006. Concrete Tests - Consistence of Freshly Mixed Concrete - Slump Test. Pretoria: South African Bureau of Standards.

SANS (South African National Standard) 2006b. SANS 5863-3: 2006. Concrete Tests-Compressive Strength of Hardened Concrete. Pretoria: South African Bureau of Standards.

Wang, Y, Backer, S \& Li, V C 1987. An experimental study of synthetic fibre reinforced cementitious composites. Journal of Materials Science, 22(12): 4281-4291.

Won, J P, Lim, D H \& Park, C G 2006. Bond behaviour and flexural performance of structural synthetic fibre-reinforced concrete. Magazine of Concrete Research, 58(6): 401-410. 